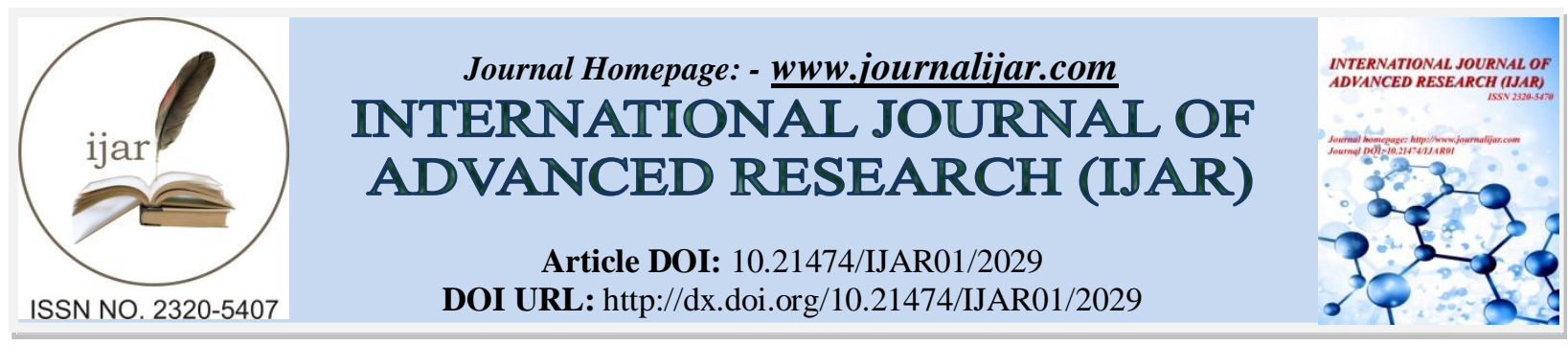

RESEARCH ARTICLE

\title{
EMPOWERING THE MSMES IN THE EMERGING MARKETS THROUGH BRIDGING THEIR FINANCE GAP: A STUDY.
}

\author{
Deepa Sahai Garg. \\ Assistant Professor, College of Vocational Studies,University of Delhi.
}

\section{Manuscript Info}

Manuscript History

Received: 27 September2016

Final Accepted: 12 October 2016

Published: October 2016

Key words:-

MSMEs, MSMED Act, NBFCs, SIDBI,

Credit, Finance.

\section{Abstract}

MSME's contribute significantly to the economy and are geographically widely spread in a country like India. The MSME sector has often been termed as the engine of inclusive growth for the promotion of the equitable development in the economy. While the sector is striving to harness its growth potential, it faces a number of challenges like lack of credit, high cost of credit, delayed payments, procurement of raw materials at a competitive cost, lack of access to global markets, inadequate infrastructure facilities, low level of technology modernisation, lack of skilled manpower marketing, revival of viable sick units, so on. Studies on SMEs financing have shown that bank credit is the major source of finance for the SMEs. But the banks and larger non-banking financial corporations have not been able to meet there demand for finance effectively as the banks desire to focus on the track record of any business instead of its future prospects. Large number of MSMEs does not yet have access to credit from the organised financial sector. The objective of this paper is to focus on the vital role played by banking sector in financing MSMEs in the emerging markets; look at some recent trends which highlight the development and significance of this sector towards the Indian economy. This paper also tries to identify the challenges faced by them in raising finance and the different sources of finance apart from banks. This paper attempts to suggest some recommendations to increase the overall credit accessibility for the MSMEs sector. The conclusion arrived through the key issuesaddressed are the creation of a more supportive enabling environment to promote MSME finance and the need for an improved financial infrastructure through deepening the delivery of credit .Conventional financing may not be enough to encourage the MSME sector and there is a dire need for some out of box thinking.

Copy Right, IJAR, 2016,. All rights reserved.

\section{Introduction:-}

The Micro, Small and Medium Enterprises (MSMEs) play a vital role in the overall economic and the social development of the country, contributing significantly to the country's manufacturing output, exports and employment often acting as the nurseries for the entrepreneurship and the innovation. MSME sector contributes 
around $8 \%$ of GDP. With more than 30 million enterprises, it provides the second largest source of employment to more than 70 million persons, contributing almost $45 \%$ to the manufacturing output and around $40 \%$ to the total exports. For the development of any economy, effective, efficient, flexible and innovative, ambitions and visionary entrepreneurial spirit is needed. MSMEs have been considered as efficient platforms for the entrepreneurial development for more economic growth and thereby promoting equitable development in the form of rural industrialisation of backward areas, reducing thereby the regional imbalances and promising equitable distribution of the national income, wealth and resources. The Micro, Small \&Medium Enterprises in India have registered tremendous growth constituting more than $90 \%$ of the total enterprises and contribute towards the generation of largest employment opportunities next to agriculture in India.The advantage of this sector is also in the creation of employment potential at comparatively low capital cost. The MSME sector is more labour intensive than the large scale sector.Their importance vastly also lies in the terms of full filling the objectives of quality production, contribution to the exports sectors, new innovations, and improved product development and last but not the least import substitution. MSME play an important role in alleviating poverty and contribute significantly towards the

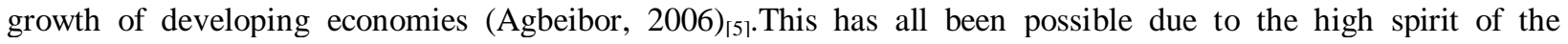
entrepreneurs in the MSME sector.For India achieving a growth rate of 8 per cent and more, it is essential that its industrial sector along with the MSMEs are growing and developing at a faster pace.More than 6000 products ranging from traditional to highly advanced technical items are manufactured in the MSME sector in India. As per the Fourth All India Census of the Micro, Small and Medium Enterprises, total number of Enterprises of the MSME sector is 361.76 lakh of which 15.64 are registered Enterprises. The sector provides employment to 805.24 lakh persons. According to the fourth census of MSME, 67 per cent of the enterprises in the registered MSMEs sector were engaged in manufacturing, whereas 17 per cent of the enterprises were engaged in the services activities. The remaining 16 per cent of the enterprises were engaged in repairing and maintenance. About 90 per cent of the firms were proprietary owned firms.

\section{Objectives of the Study:-}

Following are the main objectives of this research paper:

1. To examine the contribution made by the MSME sector as the vehicle of sustainable industrial growth.

2. To study and analyse the position of bank credit flow to the MSME sector.

3. To categorise various barriers and challenges faced by MSMEs in raising finance.

4. To identify different sources of finance other than from banks.

5. To examine the policy frameworks and various provisions for financing to a MSME.

6. To recommend for the review of these policy framework in the light of current scenarios.

\section{Methodology:-}

The use of secondary information through various published reports and other data sources from different sites such as of Ministry of Finance, Ministry of MSME, SIDBI, RBI , GOI and various banks in their committee reports, publications, speeches and the periodical journals, reports and newspapers have been made while writing this paper. This paper covers the period from 1990-91 (post liberalisation period) to 2014-15.

\section{MSME Sector- the Engine of SustainableGrowth:-}

The MSME sector has been consistently registering high growth rates as compared to the overall industrial sector in the recent years. With its agility, innovativeness and dynamism, the sector has always shown the adaptability to survive through the economic slowdowns and recession. The MSME sector is highly heterogeneous in the terms of its size of enterprises, variety of different products and services. MSMEs always complement various large industries as ancillary units and thus contribute immensely towards the socioeconomic development of any economy.

The Government of India enacted the Micro, Small and Medium Enterprises Development (MSMED) Act, 2006to provide more competitiveness of this sector and defined medium enterprises for first time. With the MSMED ACT, Ministry of Agro and Rural Industries and Ministry of Small Scale Industries were combined into a single Ministry, Ministry of Micro, Small and Medium Enterprises. Some of the features of the MSMED Act are:

- Setting up of a National Board for MSMEs, an apex advisory body constituted to provide advice to the Government on all MSME issues which brings together the representatives from sub-sectors of MSMEs, policy-makers, trade unions , bankers, and others to move towards consistent development of this sector.

- Various schemes to control delayed payments to MSMEs 
- Advisory Committees for the support to MSMEs

- Measures for the promotion and development of MSMEs

- Enactment of rules by State Governments to implement the MSMED Act, 2006 in their respective states

- Classification of enterprises

The MSMED Act 2006 defines theMicro, Small and Medium Enterprises as below:

For MSMEs in the Manufacturing Sector, the criterion for categorisation is the investment in plant and machinery which is as follow:

- Micro Enterprises: Less than Rs. 25 lakh

- Small Enterprises: Between Rs. 25 lakh and Rs. 5 crore

- Medium Enterprises: Between Rs. 5 crore and Rs. 10 crore

For MSMEs in the Service Sector, the criterion is the investment as follows:

- Micro Enterprises: Less than Rs.10 lakh

- Small Enterprises: Between Rs.10 lakh and Rs. 2 crore

- Medium Enterprises: Between Rs. 2 crore and Rs. 5 crore

In any world economy, MSME sector is the fastest evolving and growing industrial sectors. Micro, Small and Medium Enterprises are economically and socially very important for the boost to entrepreneurship and innovation. The primary key requirement for unlocking the potential success in any business and economic activity and for the growth of the entrepreneurship is availability of financein order to meet their fixed capital as well as their working capital requirements. Forgrowth,development, diversification, modernization and up gradation of facilities and for the capacity expansion of MSMEs, finance and credit support is a critical input.Finance consists of equity capital, funds for fixed asset investment and meeting cash flow gaps with working capital. The finance problem of MSMEs has been under much discussion and debate in the recent years and has been considered to be a most crucial area for the research in the field of economics and finance. The financial barriers affect the Micro and Small Enterprises in their overall development. MSMEs in India which constitute more than $90 \%$ of the total number of industrial enterprises forming the important pillar of industrial development suffers from the snags of sub-optimal scale of operation and the glitches of the technological obsolescence. This lands them in the troubles of acquiring timely bank credits.In spite of the various challenges this sector has been facing, it has shown adaptability and flexibility to survive in the recent economic downturn, turmoil and recession.

\section{Key Challenges faced by the MSME Sector:-}

It is believed that it's the large industries and corporate houses that are providing more employment. But the truth is that only 12.5 million people are given employment by them, as against 120 million people employed in the MSME sector. According to the National Sample Survey Organisation (NSSO) in 2013, there are 57.7 million small business units, mostly sole proprietorship, which undertake manufacturing, trading or services activities. These include small manufacturing units, fruits and vegetable vendors, repair shops, truck and taxi operators, street vendors, food-service units, machine operators, shopkeepers, small industries, artisans, food processors etc. But there are various bottlenecks which they have been facing. Here's an account of some of the constraints:

\begin{tabular}{|l|l|}
\hline 1 & Lack of availability of adequate and timely credit \\
\hline 2 & High cost of credit \\
\hline 3 & Collateral requirements \\
\hline 4 & Limited access to equity capital \\
\hline 5 & Problems of storage, designing, packaging and product display \\
\hline 6 & Procurement of raw material at a competitive cost \\
\hline 7 & Lack of access to global markets \\
\hline 8 & Inadequate infrastructure facilities, including power, water, roads \\
\hline 9 & Low technology levels and lack of access to modern technology \\
\hline 10 & Lack of skilled manpower for manufacturing, services, marketing, etc. \\
\hline 11 & Multiplicity of labour laws and complicated procedures associated with compliance of such laws \\
\hline
\end{tabular}




\section{Finance Gap in MSMEs:-}

While understanding as to why MSMEs have to scuffle with finances despite that there are various sources available for meeting their finance needs, one comes across various problems faced by this sector in securing loan from banks. MSMEs are generally started by young entrepreneurs, who have no or very little track record acts as a block in their way to get access to bank credit. Banks are an important source for providing finance to businesses. The banks while consideringlending to MSMEs are looking for collaterals to protect against a likelihood of Non-Performing Assets, which is not always possible for the MSMEs to afford.MSMEentrepreneur face following problems when they approach banks and hence don't prefer bank's credit:

- Firms experience delay in disbursement while sanctioning the loan, it takes almost months to get the bank credits and there is no on line system to track the loan application.

- Lengthy, inflexible and complex paper work for the disbursement of loan,

- bank official insist to give collateral security and their preference for the security obsessed lending,

- Banker's non cooperative attitude to this sector,

- Delay in sanctioning of loan.

- Various information asymmetries, higher risks, sizeable transaction costs and a lack of adequate collateral.

By practice, private funds from friends and the family members form the largest pool and source of funds to the MSMEs in India. MSMEs in India also depend heavily on money lenders and also resort to the unorganized financial sector for meeting their requirements, where the interest rates are very exorbitant and the terms of financing are not clear. This small pool of the fund providers often restricts the potentially viable and more growth oriented MSMEs out of the operation.However restrictiveapproach is followed by the banks as they have to manage the risk in any loan application for a business. A Bank has to evaluate the risks involved, check the collateral support and then look at the ways to reduce those risks. Therefore it may not always be possible for an entrepreneur to live up to all requirements and conditions of theBank. Various studies indicate that most of these small firms prefers to rely on internal financing and informal sources. These methods of financing are majorly debt financing, and the sources of equity funding remain rare in India.These problemsarefurther aggravated by institutional factors within a country.As there is no accurate data available about the MSME financing gaps, because the unorganised and unregistered sector within the MSME sector is so vast; no authentic information about them is available.

The total gap in MSME funding is estimated to be around USD 126 Billion. Out of this, the debt gap is approximately USD 84 Billion and equity GAP is about USD 42 Billion. Out of this the total equity supply is only about USD 526 million, a huge shortfall. The major reasons for creation and perpetuating of this finance gap are:

- information asymmetry which is present in Indian MSMEs,

- the family owned nature of Indian businesses, and

- lack of information regarding tapping the right kind and source of finance.

- the poor quality of projects seeking funding;

- the inability of MSMEs to make the best possible use of available resources of funding; and

- the negative attitude displayed by MSMEs towards equity financing.

\section{Main Constraints for MSME sector to access Formal Financial sector:-}

The following important issues seem torestrain the MSMEs access to the formal financial sector:

1. MSMEs in India mostly rely on their friends \& family as the source of equity. This is due to the lack of cognizance about MSMEs of various sources and schemes available as well as lack of proper governance structures in small businesses which discouragethe investors. Equity as a source of finance to MSME is underutilised and the incidence of investment by venture capital and the angel investors is very low as compared to other countries.

2. Over the ages, MSMEs problem of delayed payments from large corporate buyers, remain unsolved. This impacts their working capital and affects their next cycle of production thereby distressing their capacity to service existing debt.

3. The available credit guarantee and insurance schemes have not been fully utilised by the banks because of the conditions imposed by banks limiting the eligibility and various operational issues that delay the realisations.

4. MSMEs also lack the information about the various support schemes and benefits made to them by the government. In some cases, they lack the technical knowhow to deliver the required information to avail such schemes. 
5. The financial institutions such as banks have been facing the challenges in the correct credit risk assessment of MSMEs, due to lack of financial information, historical cash flows, past credit track record and in the absence of the above records non-availability of tools to assess credit risk .

6. Banks also complain that these first generationentrepreneurs lack the experience and fail to bring the initial promoters contribution.

7. Weak and inadequate marketing tools and globallyuncompetitive due to lack of product branding is another bottleneck.

Government Legal, Regulatory and Supportive Measures for enabling Finance to MSMEs:-

Since independence, Government of India has providedfollowing supportive measures focusing on infrastructure development, technology and quality:

- reservation of some items for the exclusive manufacture by MSMEs,

- access to credit through priority sector lending programme for commercial banks,

- excise exemption,

- reservation under Government purchase programme and 15 per cent price preferences in purchases,

- infrastructure development,

- establishment of institutes of entrepreneurial and skill development.

- MSME Development Institutes, were set up all over India to train youths and

- tool rooms were set up with the German and Danish support to provide skill training and to provide technical assistance.

- At the state level, District Industrial Centres have been setup throughout the country.

With liberalization and globalisation, government policies have also moved fromproviding protective measures to infusing more growth and competitiveness in the sector over the time. Government of India has always been conscious of the funding gap which affects the IndianMSMEs. The Government of India has introduced several support measures and regulatory schemes to enable timely financeto the MSME sector. Some of the important policies and schemes related to financial inclusiveness and technological up gradation for MSMEs are discussed in the following sections:

\section{Credit Linked Capital Subsidy Scheme (CLCSS):-}

Credit Linked Capital Subsidy Scheme (CLCSS) operated by the Ministry if MSME for the technologicalupgradationof Micro and Small Enterprises (MSEs)was launched in October 2000 and thereafter revised from 2005. The scheme targets at facilitating technology upgradaton of MSEs by providing 15\% Capital Subsidy limited to maximum Rs. 15.00 lakh, for the purchase of the plant \&machinery. Maximum limit of eligible loan for calculation of subsidy under the scheme is Rs. 100 lakh.Till now more than 1500 technologies, 51 products and sub-sectors have got the approval under the scheme. From the inception of this scheme, 30,732 units have got the subsidy of Rs. 1776.58 crores till the end of 2014.

\section{Credit Guarantee Fund Scheme for Micro and Small Enterprises:-}

With the objective of making collateral free credit available to the MSEs, the Credit Guarantee Fund Scheme for Small Industriesnow renamed as Credit Guarantee Fund Scheme for Micro and Small Enterprises was launched in 2000, particularly for Micro Enterprises, for loansup to Rs. 100 lakh without any collateral or the third party guarantees by eligible lending institutions to new and existing MSMEs. This scheme is operated by the Credit Guarantee Fund Trust for Micro and Small Enterprises jointly by the Government of India and SIDBI. The corpus of CGTMSE is contributed by the Government of India and SIDBI in the ratio of 4:1. The corpus of CGTMSE has been increased to Rs. 2389.04 crore with the contribution of Rs.1911.23 crore from the GoI and Rs. 477.80 crore from SIDBI. This includes Rs. 74.99 crorecontributed byGoI contribution during the year 2014-15.

\section{Scheme of Micro Finance Programme:-}

Since 2003-04, the Ministry has been operating a Scheme of Micro Finance Programme which is tied up with the Micro Credit Scheme of SIDBI. Under this scheme, the GOI provides funds to SIDBI under (PRF) 'Portfolio Risk Fund' which is used for security deposit. As on 31st December 2014, under the scheme, cumulative loan amount provided to MFIs and NGOs was at Rs 2199.11 crore covering around 27.19 lakh beneficiaries. SIDBI is the premier financial institution for the promotion, financing requirements and the development of the MSMEs in India. 
In the recent years, the MSME sector has shown interest in various alternative sources of funding. These are primary/secondary securities market, external commercial borrowings, venture capital and private equity, factoring services etc. Also more efforts are put for the Limited Liability Partnership Act to provide push to MSMEs to become the body corporates. The Government has been announcinginitiatives for stepping up credit to SMEs in last five years to rejuvenate the MSME sector with the broad objective of doubling the credit flow to them.BSE and NSE havegot the approval for the SME platforms from SEBI and have become operational serving as the prospect for Indian SMEs to raise financefrom thecapital markets.

\section{Mudra (Micro Units Development and Refinance Agency)Bank:-}

MUDRA Yojana was announced during Union Budget for FY 2016. The Government has decided to set up 'Mudra Bank', a refinance agency to be introduced with a corpus of Rs 20,000 crore, and with a credit guarantee fund of Rs 3,000 crore with focused lending to MSMEs. MUDRA Bank is a public sector financial institution in India. This bank will address the working capital and funding shortfall faced by MESs.Under the guideline of PradhanMantri MUDRA Scheme, MUDRA Bank has launched its three initiative product and their names are SHISHU, KISHOR $\&$ TARUN. It provides loans at low rates to micro finance institutions and NBFCs which will then provide credit to MSME's.MUDRA Bank is refinancing through State level institutions, MUDRA bank will provide the loan through NBFCs, MFIs, Rural Banks, District Banks, Nationalize Banks, Private Banks, Primary Lending Institutions and other intermediaries.

\section{India Aspiration Fund (IAF) and SIDBI Make in India Loan for Enterprises (SMILE):-}

Two funds the India Aspiration Fund (IAF) and SIDBI Make in India Loan for Enterprises (SMILE) under SIDBI in line to fulfil the funding for the start-ups and to help the small enterprises in India have been launched. SIDBI and Life Insurance Corp. of India (LIC) as a partner and co-investor under the IAF would invest in the venture capital funds for meeting the equity requirement of MSME start-ups.the initial corpus of Rs. 2,000 crore has been set for this. Inthe second debt fund, the SMILE will meet the soft term loans to MSMEs to meet debt-to-equity norms and pursue growth opportunities. SIDBI has set the Initial corpus of Rs. 10, 000 crore under this fund. Finance Ministry has launched these funds under SIDBI.

\section{Committee to examine the financial architecture set up:-}

A Committee to study the financial architecture of the MSME sector was constituted by the Department of Financial Services; Ministry of Finance in 2014.The approach of the committee towards the financial architecture for MSME incorporates the following key elements:

- encouragingthe registrations;

- opening of more bank accounts;

- easyaccess to equity financing;

- creation of a platform for receivables financing;

- expansion and enhancing the guarantee cover;

- and increasing the distribution and reach through a wider base of financial intermediaries, toprovide the finance to a large number of MSMEs in the country .

\section{Conclusion:-}

Credit flow and the availability of the timely and less costly funding options are needed for the growth and development of the MSMEs.A vibrant global economic scenario has put up numerous opportunities and challenges for the MSME sector in India. On the one hand, various opportunities have unwrapped up for this sector new national and international markets and to enhance productivity .On the other hand, these numerous opportunities compel the MSMEs to keep upgrading their skills, competences and technologies to strugglewith biggercompetition since technological obsolescence is quick with new products are being launched at an fast pace and are available to the world at large in a short time. Thus the importance of timely provision of funds to them .Though the bankers have maintained that lending to MSMEs is growing at around 20-22\% year-on-year even then overall demand for the credit exceeds the credit flow to them. Several policies, regulatory and institutional initiatives have been taken to promote availability of finance to MSMEs. These include, among others, credit support mechanisms administered by government institutions. In recent years, many NBFCs such as Indiabulls, Edelweiss, Indostar Capital and IIFL have also turned their focus to the small businesses and the professionals. With the global economic slowdown hitting, lending to the bigger industries have become more riskier. If lending is made to small professionals like doctors and the architects, there can never be a recessionary period. As compared to the banks, 
paper work is easier and the application processing times are also less which is the reason more MSMEs are driven towards NBFCs for loans. The creation of a financial architecture for the MSME sector that would uses technology driven platforms to provide financing to the large number of MSMEs which do not have access to credit and thereby providing more financial inclusion is the need of the times. Simple and easier registration and facilitation procedures, strong guarantee programmes,financial inclusion, and a bigger distribution network should improve the relation between unbanked MSMEs and the vast financial system.

\section{References:-}

1. Annual Report 2014-15, Ministry of Micro Small and Medium Enterprises 2.http://shodhganga.inflibnet.ac.in/bitstream/10603/6582/11/11_chapter2.pdf, pg 14, 15

2. msme.gov.in/.../2015_02_MSME_Committee_report_Feb_2015, Report on Financial Architecture for MSMEs Ministry of MSME.

3. Micro, Small and Medium Enterprise Finance in India (2012), a research study on needs, gaps and way forward, by IFC.

4. Nishanth P and Zakkariya KA (May, 2014) barriers faced by micro, small and medium enterprises in raising finance, abhinavjournal.com/journal/index.php 51, 40-43,

5. https://www.dnb.co.in/SME_cluster.../PDF/MSMEs_in_India.pdf

6. www.moneycontrol.com > SME Stepup > Policy Watch, Budget 2015: What's in it for MSMEs?

7. www.sidbi.com

8. www.dcmsme.gov.in/schemes/sccrguarn.htm, Credit Guarantee Scheme - DC-MSME

9. www.yesbank.in > Knowledge Banking > YES SME, Role of the Government in SME Financing

10. www.business-standard.com/.../pm-launches-mudra-bankto-fund-micro, PM launches MUDRA Bank to fund small businesses

11. http://currentaffairs.gktoday.in/finance-minister-launches-funds-promoting-msmes-start-ups-08201525934.html 